\title{
Reflections on Mirror Coating Materials
}

The Historical Note in the October 1988 MRS BULLETIN described the background and problems involved in casting some of the giant glass mirror blanks used in the world's largest reflecting telescopes. This Historical Note takes an about-face to look at the other side of a mirror-the reflective coating that makes it what it is. Reflective coating materials for mirrors have changed through the ages, in material and process, going from polished metallic surfaces to thin metal films applied by chemical and physical methods.

People have been using various reflecting tools to see themselves since the first human looked at his image in a still pool of water. The Egyptians used polished bronze, gold, and silver mirrors as early as 2500 B.C. The ancient Greeks added handles to their mirrors, while the Etruscans used round and oval mirrors (6th Century B.C.). The Romans copied both styles. In the first century A.D. the Roman naturalist Pliny the Elder described how the inhabitants of the Phoenician city of Sidon had learned how to coat glass with silver or tin, but this type of mirror seems to have been little used, and the art died out in the Dark Ages.

In the late 12th and early 13th centuries, craftsmen learned how to apply metallic backings to flat glass, using steel and silver almost exclusively.

In the late 12th and early 13th centuries, craftsmen learned how to apply metallic backings to flat glass, using steel and silver almost exclusively. The city of Nuremberg formed its own guild of mirror makers in 1373 and, by the time of the Renaissance, Nuremberg, along with Venice, had earned a reputation as a major center of mirror production. The mirrors produced in Venice were famed for their ornate frames and beveled edges, and Venice became Europe's major supplier of mirrors for several centuries. The techniques of mirror making eventually slipped out of the tightly controlled Venetian guilds, and London and Paris also became important mirror manufacturing centers. But mirrors themselves remained extremely expensive, especially large ones.

In the 16th century, Venetian mirror makers introduced a major new technique when they began to use an amalgam of tin and mercury as a reflective backing. Guildsmen would lay out a sheet of tin foil on a horizontal blanket over a flat surface, and then spread clean mercury on the foil. A covering of paper kept the mercury clean. Workers then cleaned a sheet of glass and lowered it onto the paper-but they drew away the paper just as the glass was about to touch, which allowed the clean glass to contact the clean mercury. Heavy weights placed on the glass sheet squeezed out the excess mercury, and the amalgam adhered to the glass. Along with improved methods of pouring plate glass sheets, this technique created highly reflective mirrors of considerable size and quality.

While perfect for most popular uses, glass mirrors backed with reflective coatings were useless for precise scientific purposes. For careful measurements the reflective coating must be on the front of a mirror, not the back, to eliminate light losses and distortions, as well as spurious reflections and aberrations, caused by the thickness of the glass. Using the tin and mercury amalgam method to coat the front surfaces of scientific mirrors yielded results that were dull and irregular.

In 1663, Isaac Newton began experimenting with optics and reflections. He operated under the assumption that all substances possessed the same "dispersive power," which (erroneously) led him to conclude that it was impossible to eliminate or suppress chromatic aberration in any instrument consisting of a system of lenses. He turned his attention toward using magnifying mirrors as the main optical component of his telescope.

Magnifying mirrors formed on curved pieces of glass had initially appeared in the 13th century. Newton produced his first reflecting telescope in 1668 , but it was very small-6.25 inches long, with a mirror only 1.25 inches in diameter! He worked with mirrors made of solid metal, a highly reflective alloy of tin and copper called "speculum," which became the standard for astronomical mirrors for the next two centuries.

In the mid-19th century, telescope maker Sir Howard Grubb wrote: "The composition of metallic mirrors of the present day differs very little from that used by Sir Isaac Newton (1643-1727). Many and different alloys have been suggested, some including silver or nickel or arsenic, but there is little doubt that the best alloy [speculum] is made with four atoms of copper, and one of tin."

\section{The art of mirror making seemed at a standstill until 1835, when German chemist Baron Justus von Liebig invented "silvering."}

Speculum metal disks were difficult to configure, though. The alloy was brittle and difficult to cast, and still reflected only about $60 \%$ of the incident light even when freshly polished. Efforts to improve the casting and figuring of speculum mirrors continued long after Newton's death in 1727. British astronomer William Herschel made his own speculum mirrors because they were too expensive for him to buy, and in so doing he advanced the art of working with the alloy. The largest speculum mirror ever made was 72 inches in diameter, constructed by Irish amateur astronomer Lord Rosse in 1845.

The major problem with speculum was that the copper caused the polished surface to tarnish rapidly, necessitating frequent repolishings. These repolishings destroyed the careful configuring of the curved mirror surfaces-every time the mirror was polished it had to be remade, in effect. In addition to the cost involved, this removed an astronomer's telescope from service for weeks, causing disastrous gaps in long-term observations.

The art of mirror making seemed at a standstill until 1835, when the highly successful German chemist Baron Justus von Liebig invented "silvering," a chemical process of coating a glass surface with metallic silver. During his career, Baron von Leibig made so many important contributions to organic chemistry, biochemistry, agricultural chemistry, and chemistry edu- 
cation that his invention of the silvering process receives only incidental mention in his biographies.

However, for mirror makers the silvering process revolutionized the industry. In silvering a mirror, the glass is coated with an ammonium hydroxide-silver nitrate solution that is reduced to metallic silver. The reducing agent can be invert sugar, Rochelle salt, or formaldehyde, which then precipitates a layer of metallic silver onto the glass. The process was originally quite hazardous because the reaction created highly unstable ammonium nitrate.

Copper and gold can be deposited on mirrors by similar chemical reduction techniques. The thickness of gold films can be manipulated by controlling the heating of an organic gold compound. A film of lead sulfide deposited on glass will yield a darkcolored mirror.

The silvering process could be used to provide a uniform coating over any shape of glass surface. In 1856 the German astronomer Karl August von Steinheil developed a method to use silvering to coat glass blanks for telescope mirrors. The major advantage of using silvered glass blanks instead of solid speculum mirrors, von Steinheil found, was that when the silver film became tarnished, it could be quickly removed with acid and a bright new coating applied-all without affecting the carefully configured surface of the glass blank.

Fresh silver coatings have a reflectivity of about $96 \%$ throughout the visible spectrum, the highest of any metal, but begin to drop off at a wavelength of about $4,500 \AA$ and become useless in the ultraviolet regions. In 1935 this, along with the speed that silver tarnishes, prompted John Strong in California to develop a process to deposit aluminum films on mirrors.

Aluminum can be deposited on a mirror surface by electrically heating an aluminum filament in a vacuum and allowing the aluminum to evaporate onto the glass. Although aluminum has a slightly lower reflectance in the visible region $(87 \%$ instead of $96 \%$ for silver) aluminum retains its high reflectivity from the ultraviolet to the infrared, and it does not tarnish so rapidly. Most astronomical mirrors now use aluminum coatings applied with Strong's process.

Other reflective materials investigated proved to be less effective. Chromium, nickel, manganese, and titanium all have reflectances of only about $60 \%$, while platinum, palladium, and rhodium do a little better, reflecting between $70-80 \%$ of the incident light. Magnesium fluoride films tend to be effective only in the ultraviolet range, especially from $1,000-1,700 \AA$.
In some optical and physical applications, mirrors must be only partly silvered to reflect and transmit specific amounts of the incident light. This must be done slowly enough for the manufacturer to control the precise amount of coating deposited. "Sputtering," or high-voltage discharge between electrodes in a vacuum, is also used to deposit metallic coatings on mirrors.

Many other types of coatings are used in mirrors and scientific optical systems, including antireflection coatings, protective coatings for the aluminized surfaces of mirrors, or reflective coatings of other metals to optimize reflection in one specific wavelength range at the expense of others.

Reknowned French optician Colonel Charles Devé wrote in 1942: "The silvering of mirrors has become such a normal practice that it might be believed to be finally settled. Nevertheless other, very recent, methods of metallisation seem likely to modify the technique of mirror making profoundly." Indeed, the chemical silvering process is still used today, although it has been supplanted with other more precise techniques.

KEVIN J. ANDERSON

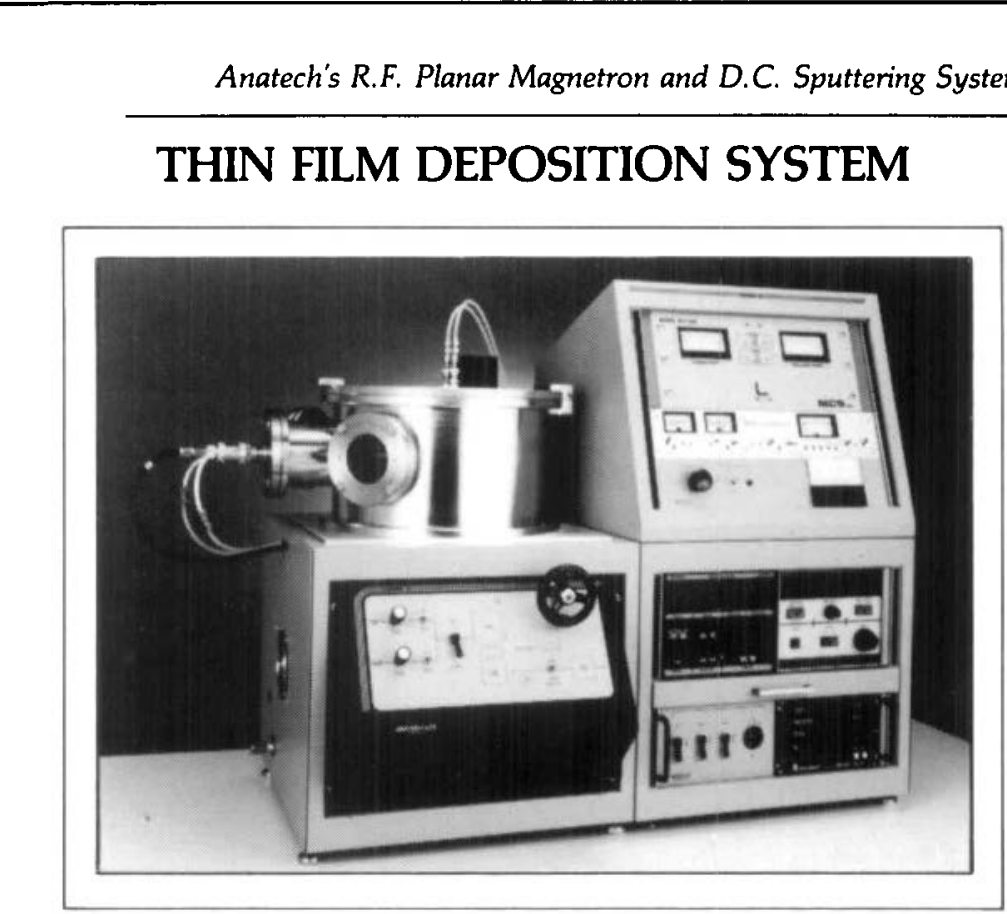

Anatech LTD offers the Research XII RFPM research sputtering system for this film deposition. The System is table top, designed for simple operation, and is capable of sputtering a broad range of materials by either RF or DC power.

The system can be configured with various options, including additional sputtering sources and power supplies, ion beam source, temperature and thickness control, heated or cooled stage, and pumping capacity.

Call or write today for techical information.

\section{ANATECH LTD}

5510 Vine Street, Alexandria, Virginia 22310 Telephone (703) 971-9200

Telex 858531

Fax 703-971-4818

Please visit Booth No. 109 at the MRS Show in San Diego, April 25-27. 